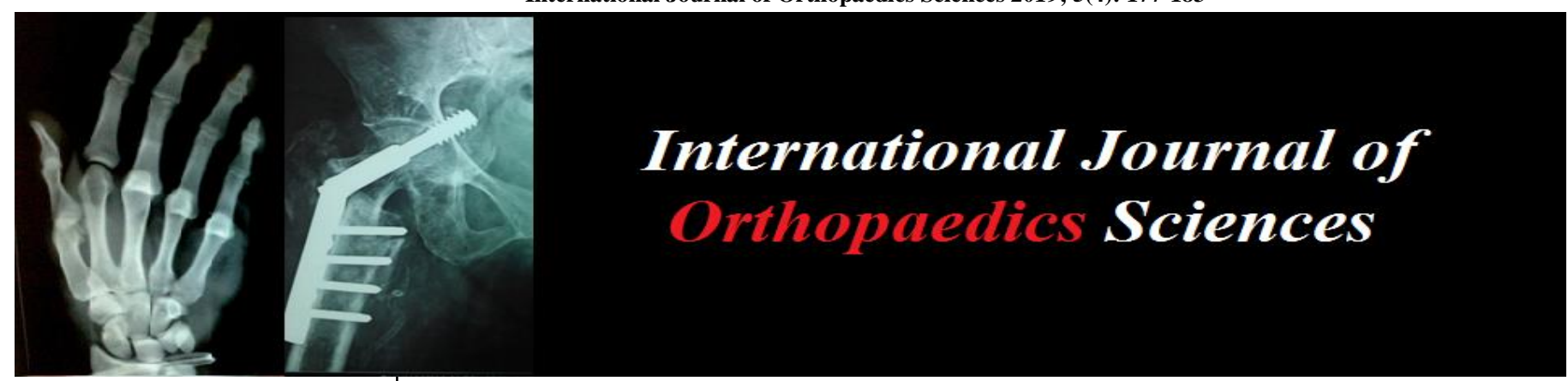

E-ISSN: 2395-1958

P-ISSN: 2706-6630

IJOS 2019; 5(4): 177-183

(C) 2019 IJOS

www.orthopaper.com

Received: 09-08-2019

Accepted: 13-09-2019

Dr. Vishal Ashokraj Pushkarna Assistant Professor, Orthopedics Department, Gujarat Adani Institute of Medical Sciences, Bhuj, Kutch, Gujarat, India

Dr. Thadamalla Vikram Senior Resident, ESIC Medical College and Hospital, Orthopedics Department Sanathnagar, Hyderabad, Telangana, India
Corresponding Author: Dr. Vishal Ashokraj Pushkarna Assistant Professor, Orthopedics Department, Gujarat Adani Institute of Medical Sciences, Bhuj, Kutch, Gujarat, India

\section{Results of proximal femoral nail in unstable intertrochanteric fracture of femur}

\author{
Vishal Ashokraj Pushkarna and Thadamalla Vikram
}

DOI: https://doi.org/10.22271/ortho.2019.v5.i4d.1669

\section{Abstract}

Introduction: Intertrochanteric Femur fractures comprise approximately half of all hip fracture caused by low energy mechanism. These hip fractures occur in characteristic population with risk factors including increasing age, female gender, osteoporosis, a history of fall and gait abnormality. In spite of great advances made in the field of trauma in last 50 years, management of this fracture has always remained subject of debate. There are several internal fixation options for managing these fractures that generally fall into two categories: some form of intramedullary fixation or some form of plating. Proximal Femoral Nailing is load bearing device with rotational stability and also short lever arm in addition to indirect fracture reduction. In this article we will discuss the role of proximal femoral nail in unstable intertrochanteric femur fracture.

Materials \& Methods: We have done a prospective study in 40 patients of unstable intertrochanteric femur fractures of femur operated with proximal femoral nailing at our institute with follow up of $5-24$ months. All patients above 31 years of age with proximal femur fractures of femur admitted in tertiary center meeting the inclusion and the exclusion criteria during the study period were the subjects for the study. Patient were regularly followed up radiologically. Final outcome is measured with Harris Hip Score.

Results: In the present study, 40 cases of unstable intertrochanteric fractures treated operatively with proximal femoral nail (PFN), and the results were analyzed. In this series, low velocity injury (Domestic fall) was the cause of fracture in the majority $(70 \%)$, especially in the elderly female patients. The operations were completed within 2 hours in $98 \%$ of the patients. For PFN minimum duration was 40 minutes and maximum duration was 150 minutes and mean duration was 80 minutes. One patient had outward migration of screw, one patient had backout of derotation screw, 7 patient had varus collapse, five patient had abductor weakness on followup. On 6 month follow up thirty patient had separated lesser trochanter with union of fracture but there was no limitation of movement $\&$ any residual deformity. The functional result according to Harris Hip Score was found to be excellent in $54 \%$, good in $26 \%$, fair in $10 \%$ and poor in $10 \%$ of patients.

Conclusion: Intertrochanteric fractures commonly occur in elderly persons, usually following minor trauma whereas in young patients a major trauma is needed to cause this fracture. Proximal femoral nail offer less invasive option for fixation of unstable intertrochanteric hip fractures. Unstable fractures can be fixed faster and with lesser soft tissue dissection. On basis of our study we have concluded that PFN should be considered for management of unstable intertrochanteric fractures in young as well as elderly patients who have multiple pre-existing illness.

Keywords: unstable intertrochanteric femur fracture, proximal femoral nailing, PFN, IT fracture

\section{Introduction}

Intertrochanteric Femur fractures comprise approximately half of all hip fracture caused by low energy mechanism. These hip fractures occur in characteristic population with risk factors including increasing age, female gender, osteoporosis, a history of fall and gait abnormality. In spite of great advances made in the field of trauma in last 50 years management of this fracture has always remained subject of debate. There are several internal fixation options for managing these fractures that generally fall into two categories: some form of intramedullary fixation or some form of plating. Proximal Femoral Nailing is load bearing device with rotational stability and also short lever arm in addition to indirect fracture reduction. Appropriate selection of implant, 
good reduction intraoperatively and proper surgical technique from the surgeon's point of view can minimize the risk of failure and necessity for reintervention.

Due to largest tertiary care hospital large number of patient having intertrochanteric fracture are treated at our institute therefore, in present series, we have studied cases of unstable Intertrochanteric Femur fractures and their management with Proximal Femoral Nailing in 70 cases.

\section{Material \& Methods}

We have done a prospective study proximal IT femur fractures of femur operated with proximal femoral nailing at our institute with follow up of 5-24 months.

Methods of collection of data

- By History

- By follow up at interval of 1, 2, 4 and 6 months

- By clinical examination

- $\quad$ By analyzing case papers

On admission, patient was first examined thoroughly in primary survey for vital data and other major associated injuries in head, thorax, abdomen or spine along with local injuries.

\section{Proximal femoral nailing \\ Surgical steps}

Patient were given spinal or epidural anesthesia and shifted to a spica fracture table in a supine position with perineal post. Operative leg was slightly adducted and put on traction. Opposite limb was put in a full abduction as to give space for the $\mathrm{C}$-arm in between the legs. Reduction was achieved by traction and internal rotation primarily mid adduction or abduction as required. Reduction was checked in a C-arm with anterior -posterior and lateral view.

Methods to achieve reduction by closed means:

- If indirect reduction was not satisfactory the following methods were used

- Insertion of stein mann pin in the proximal fragment and manipulation so as to correct the deformity.

- Manipulate the proximal fragment with nail insertion

- Maintaining relative adduction in operative limb by;

- Pulling the chest and abdomen part of the patient towards the normal unaffected side by servant or chest straps.

- Keeping the jig close to the body and inserting the nail in this position.

Limb was scrubbed, then painted and draped under sterile condition, A $5 \mathrm{~cm}$ incision was taken above the tip of the greater trochanter and deepened to the gluteus medius muscle. Tip of the greater trochanter palpated and minimal muscle attachment was cleared off.

\section{After this PFN was fixed in a following manner \\ - Entry Point}

Entry point taken with awl/guide pin over a protector sleeve, It should be on the tip of the greater trochanter AP and lateral position

\section{- Guide wire insertion}

Guide wire: $2.8 \mathrm{~mm}$ guide wire is inserted in to the femoral shaft and across the fracture site in $6^{0}$ of valgus: Its position is checked in the $\mathrm{C}$-arm and the entry is widened with the awl.

\section{- Reaming of the proximal femur}

Reaming: Reaming of the proximal femur is done up to the proximal part of the nail to be introduced.

\section{- Nail insertion}

Nail insertion: Nail is fixed on the jig and the alignment is checked. Then the nail is inserted into the femur. The position of the holes for the proximal screws is checked in the C-arm for the depth of the nail.

\section{- $\quad$ Placing the guide wire pins}

Guide pins for the screws: Guide wires for the screws are inserted via the jig and the drill sleeve. The ideal position of the guide wires is parallel and in the lower half of the neck in AP views, in a single line in the center of the neck in the lateral views. The guide pins are inserts up to $5 \mathrm{~mm}$ from the articular surface of the femoral head and size of the lag screw determined. Reaming and tapping for lag screw done.

\section{- Insertion of the screw}

First the $8 \mathrm{~mm}$ hip screw is inserted after reaming over the distal one and then the $6 \mathrm{~mm}$ neck screw. The hip screw should be $5 \mathrm{~mm}$ away from the subchondral bone.

- Distal screws: One or two static or dynamic $4.9 \mathrm{~mm}$ interlocking bolts are inserted in to the distal pan of the nail. Out of which one is a static and another is dynamic hole. It should be done after removing the traction along with the tightening of the proximal screws. It is done free hand with the help of Image Intensifying Television and the jig is removed. The final position of the nail is checked in the $\mathrm{C}$-arm in both views and the wound was closed in layers. Patient was given the IV broad spectrum cephalosporin one dose pre-operatively and followed BID dose till $72 \mathrm{hrs}$ depending on the condition of the wound and patient.

\section{Following parameters were noted intra-operatively}

1. Total time of the surgery.

2. Blood loss: It was counted approximately by counting $50 \mathrm{ml}$ per mop used.

\section{Post operative protocol}

- Antibiotics: inj. Ceftriaxone 1gm i.v. 12 hrly was continued for first 7 days and then it was shifted to oral.

- Suction drainage was removed after 48 hours in case of open reduction.

- I.V. analgesics were given for 1 day followed by oral analgesics when necessary.

- Quadriceps physiotherapy: Strengthening exercises, Static quadriceps exersise and calf pumping are started as soon as the patient is out of anesthesia, followed by Knee and Ankle mobilization on post op day 1.

- Sutures were removed on $12^{\text {th }}$ post operative day.

- Patients were advised to walk non weight bearing walking (NWBW) as soon as tolerable usually after suture removal.

- Partial weight bearing walking (PWBW) was started once further collapse is not expected radiologically around 8 weeks

- Full weight bearing walking was allowed after assessing for radiological and clinical union.

- Hospital stay: Patient is discharged as soon as the wound and general condition of the patient is satisfactory, around $5^{\text {th }}$ post operative day.

- Follow up: Patient was asked to come for follow up 1, 2, 3 and 6 months from the date of surgery. At each follow up patient was assessed clinically as per Harris Hip score and $x$ ray AP/LAT view of hip with femur is taken. 
Post operative assessment done by using the Harris Hip Score (HHS) Grading.

Successful result

$\begin{array}{lll}<70 & = & \text { Poor } \\ 70-79 & = & \text { Fair }\end{array}$

Harris hip score
$80-89$

$90-99$

Study Hip:

IR Number:

Interval:

\section{$=$ Good \\ $=\quad$ Excellent \\ Left Right}

Table 1: Assessment by harris hip score

\begin{tabular}{|c|c|}
\hline 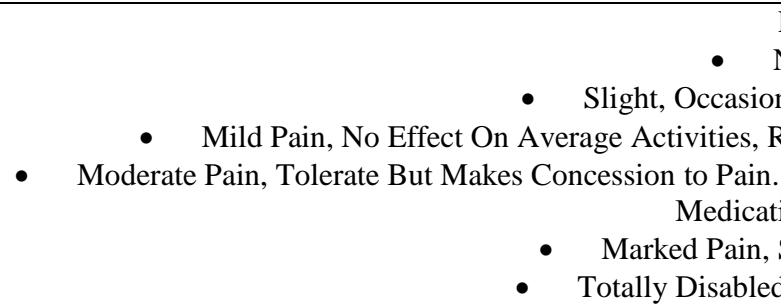 & $\begin{array}{l}\text { Activities (40) } \\
\text { ith Unusual Activity; May Take Aspirin (30) } \\
\text { dinary Activity or Work. May Require Occasional Pain } \\
\text { rin (20) } \\
\text { activities (10) } \\
\text { Bedridden (0) }\end{array}$ \\
\hline $\begin{array}{cc} & \text { Limp } \\
\bullet & \text { None (11) } \\
\text { - } & \text { Slight (8) } \\
\text { - } & \text { Moderate (5) } \\
\text { - } & \text { Severe }(0) \\
\end{array}$ & $\begin{array}{cc} & \text { Stairs } \\
\text { - } & \text { Normally Without Using A Railing (4) } \\
\bullet & \text { Normally Using A Railing (2) } \\
& \bullet \quad \text { In Any Manner (1) } \\
\bullet & \text { Unable To Do Stairs (0) }\end{array}$ \\
\hline $\begin{array}{cc} & \text { Support } \\
& \text { None (11) } \\
\text { • } & \text { Cane For Long Walks (7) } \\
\bullet \quad \text { Cane Most Of Time (5) } & \text { One Crutch (3) } \\
\text { - } \quad \text { Two Crutches/Not Able To Walk (0) }\end{array}$ & $\begin{array}{cc} & \text { Distance Walked } \\
& \bullet \quad \text { Unlimited (11) } \\
\bullet \quad \text { Six Blocks (8) } \\
\bullet \quad \text { Two Or Three Blocks (5) } \\
\bullet \quad \text { Indoors Only (2) } \\
\text { - Bed And Chair Only (0) }\end{array}$ \\
\hline $\begin{array}{c}\text { Range Of Motion Scale } \\
211^{0}-300^{0}(5) 61^{0}-100^{0}(2) \\
61^{0}-210^{0}(4) 31^{0}-60^{0}(1) \\
01^{0}-160^{0}(3) 0^{0}-30^{0}(0)\end{array}$ & $\begin{array}{c}\text { Put Shoes And Socks } \\
\text { With Ease (4) } \\
\text { With Difficulty (2) } \\
\text { Unable (0) }\end{array}$ \\
\hline $\begin{array}{c}\text { Sitting } \\
\text { Comfortably In Ordinary Chair For One Hour (5) } \\
\text { On A High Chair For 30 Minutes (3) } \\
\text { Unable To Sit Comfortably In Any Chair (0) }\end{array}$ & $\begin{array}{c}\text { Range Of Motion }(* \text { Indicates Normal) } \\
\text { Flexion }\left(* 140^{0}\right) \\
\text { Abduction }\left(* 40^{0}\right) \\
\text { Adduction }\left(* 40^{0}\right) \\
\text { External Rotation }\left(* 40^{0}\right) \\
\text { Internal Rotation }\left(* 40^{0}\right)\end{array}$ \\
\hline \multicolumn{2}{|c|}{$\begin{array}{l}\text { Absence Of Deformity (All Yes }=4 \text {, Less Than } 4=0 \text { ) } \\
\text { Less Than } 300 \text { Fixed Flexion Contracture Yes No } \\
\text { Less Than } 100 \text { Fixed Abduction Yes No } \\
\text { Less Than } 100 \text { Fixed Internal Rotation In Extension Yes No } \\
\text { Limb Length Discrepancy Less Than } 3.2 \text { Cm Yes No }\end{array}$} \\
\hline $\begin{array}{c}\text { Inter Public Transportation } \\
\text { Yes (1) } \\
\text { No }(0)\end{array}$ & $\begin{array}{l}\text { Total Harris Hip Score } \\
\text { Range Of Motion Score }\end{array}$ \\
\hline
\end{tabular}

\section{Observation \& Results}

\section{- Age incidence}

The commonest age group for unstable intertrochanteric fractures is between $61-70$ years (34\%) followed by 51-60 years $(23 \%)$ \& least common is $<40$ years.

\section{- Sex incidence}

In this series Male: Female ratio 2:3. (Because of post menopausal osteoorosis)

\section{- Mode of injury}

The majority of the unstable intertrochanteric fractures occurred following low velocity trivial trauma mostly associated witha domestic accident like fall in bathroom or fall from stairs.

\section{- $\quad$ Side of fracture}

In our study right sided fractures are more common.

\section{- Associeted comorbid condition}

Hypertension is more common co morbid condition followed by diabetes.

\section{- Anesthesia}

Out of 40 patients 35 patients operated under spinal anesthesia. 5 patients operated with general anesthesia.

\section{- Operating time (In minutes)}

Proximal femoral nailing is simple procedure and can be completed in short duration. In our study average time for procedure was $80 \mathrm{~min}$. Cases with other fracture and other procedure has taken longer time.

\section{- Duration of hospitalisation}

Majority of the patients $(60 \%)$ were discharged before $10^{\text {th }}$ post operative day, while $(40 \%)$ needed longer hospital stay. 


\section{- Starting of weight bearing}

Weight bearing can be classified into two parts, Partial weight bearing \& Full weight bearing

Table 2: Limb Length Discrepancy (At 6 Month Follow Up)

\begin{tabular}{|c|c|c|c|}
\hline & $<\mathbf{1 ~ c m}$ & $>\mathbf{1 ~ c m}$ & Normal \\
\hline No of pt & 7 & 4 & 29 \\
\hline
\end{tabular}

Most of patientsare with equal limb length.13 patients have $<1$ and 6 patients have $>1 \mathrm{~cm}$ limb length discrepancy.

Table 3: Assessment of Reduction

\begin{tabular}{|c|c|}
\hline Assessment & No. of Patients \\
\hline Acceptable & $31(77.5 \%)$ \\
\hline Poor & $09(22.5 \%)$ \\
\hline Total & 40 \\
\hline
\end{tabular}

The above table shows that reduction was acceptable in $77.5 \%$ cases with PFN, while it was poor in $22.5 \%$.

Anatomical alignment of the fracture or a valgus type or a diamond hughston variety of reduction were considered as acceptable reduction, which provide immediate stability and Poor reduction was that with no medial cortical contact and a varus of more than ten degrees compared to the opposite side.

Table 4: Partial weight bearing

\begin{tabular}{|c|c|}
\hline Duration in weeks & PFN \\
\hline Within 1st week & $0(0 \%)$ \\
\hline $1-3$ & $5(12.5 \%)$ \\
\hline $4-6$ & $15(37.5 \%)$ \\
\hline $7-10$ & $20(50 \%)$ \\
\hline Total & $40(100 \%)$ \\
\hline
\end{tabular}

In the PFN group $12.5 \%$ of patients were allowed partial weight bearing within 3 weeks of surgery, while $87.5 \%$ of patients after 3 weeks of surgery.

Table 5: Full weight bearing

\begin{tabular}{|c|c|}
\hline Duration in weeks & No. of Patients \\
\hline $8-10$ & $10(25 \%)$ \\
\hline $10-14$ & $20(50 \%)$ \\
\hline$>14$ & $10(25 \%)$ \\
\hline Total & $40(100 \%)$ \\
\hline
\end{tabular}

Table 6: Local complications

\begin{tabular}{|c|c|c|}
\hline Local Complications & Number & Percentage \\
\hline Screw backout & 1 & 3 \\
\hline Implant failure & 1 & 3 \\
\hline Peri-implant fracture & 0 & 0 \\
\hline Non-union & 2 & 5 \\
\hline Malunion & 1 & 3 \\
\hline Infection & 1 & 3 \\
\hline AVN & 1 & 3 \\
\hline Varus Malalignment & 7 & 18 \\
\hline
\end{tabular}

The total no of patients with complications was 15 (38\%). More than one complication occurred in the same patient. Incidence of complications related to implant cut-out, implant migration correlated with patient specific factors, such as advanced age, presence of osteoporosis and position of implants, irrespective of the type of implant used. There are only two case of infection and both were suffering from DM. The infection was mainly two type; one patient had superficial infection \& other had deep infection extending up to bone surface superficial infection was treated with debridement \& iv antibiotics \& deep infection was treated with removal of implant. Perimplant fracture was treated with revision \& reimplant.

Implant failure is also because of deficient lateral wall, proximal communition \& lack of medial wall continuity. One Patient had bilateral avascular necrosis with fracture intertrochanteric. Replacement was offered to patient but patient insisted for fracture treatment only. Due to this only proximal femoral nail done. Final follow up fracture is completely united with some limitation of movement. Another patient had severe posteromedial comminution with iatrogenic basicervical fracture intraoperatively. On follow up fracture was united with good clinical outcome.

In one patient there was outward migration of derotation screws that was replaced by cannulated cancellous screw at 2 month but on follow up fracture union had occurred. Two patients had backout of derotation screw \& fracture was united. On follow up that screw removal was done and patient was doing well.Ten patient has varus collapse of fracture on final follow up but it didn't complain on routine day to day activity. Five patient had abductor weakness which was corrected on successive follow up by physiotherapy. In our study thirty patient had unstable fracture with separated lesser trochanter fragment. On follow up union was seen in that patient with no any limitation of movement.

Table 7: Time of radiological union

\begin{tabular}{|c|c|}
\hline Fracture line & PFN \\
\hline Visible & $10(25 \%)$ \\
\hline Not visible & $30(75 \%)$ \\
\hline Total & $40(100 \%)$ \\
\hline
\end{tabular}

The fracture line was visible in x-rays in only $25 \%$ of patients, while $75 \%$ showed radiological union at six months.

Table 8: Results based on harris hip score

\begin{tabular}{|c|c|c|}
\hline Results & No of pt & Percentage \% \\
\hline Excellent & 21 & $54 \%$ \\
\hline Good & 10 & $26 \%$ \\
\hline Fair & 04 & $10 \%$ \\
\hline Poor & 05 & 10 \\
\hline
\end{tabular}

In study of 40 patients we obtained approximately $53 \%$ (21 Patients) excellent results and $25 \%$ good results. All of them performing their routine normal activity well. 5 patient having poor results

\section{Discussion}

Intertrochanteric fracture commonly occurs in elderly patients, but increased mechanization and increased number of road traffic accidents results in this fracture occurring even in younger patients. There are various implants available for managing unstable intertrochanteric fractures till date, but the search is still going on to decide the best method. In the present study, 40 cases of unstable intertrochanteric fractures treated operatively with proximal femoral nail (PFN), and the results were analyzed. In this series, low velocity injury (Domestic fall) was the cause of fracture in the majority (70\%), especially in the elderly famale patients. The operations were completed within 2 hours in $98 \%$ of the patients. For PFN minimum duration was 40 minutes and maximum duration was 150 minutes and mean duration was 80 minutes.

All patients were operated on fracture table and the reduction 
was checked prior to surgery in the form of AP and lateral views by Image intensified television in all the cases. On final follow up one patient had iatrogenic basicervical fracture, one patient had outward migration of screw, two patient had backout of derotation screw, 07 patient had varus collapse, five patient had abductor weakness on follow-up. On 6 month follow up thirty patient had separated lesser trochanter with union of fracture but there was no limitation of movement \& any residual deformity. On review of literature very few such comparative studies were found and out of which largest international series was that of J. Pajarinen et al. From Helsinki University Central Hospital, Helsinki, Finland and The Indian series was that of M. Porecha et al. M.P. Shah medical college, Guru Govind Singh hospital, Jamnagar, Gujarat, India. I have made comparison of my results with results of these two studies.

Table 9: Comparison for intra-operative data is as follows

\begin{tabular}{|c|c|c|c|c|}
\hline No & & Our series & J. Pajarinen's series & M. Porecha's Series \\
\hline & Anaesthesia & & & \\
1. & Spinal & $88 \%$ & $95 \%$ & $100 \%$ \\
& General & $12 \%$ & $05 \%$ & $00 \%$ \\
\hline 2. & Open reduction & $0 \%$ & $0 \%$ & $6 \%$ \\
\hline 3. & Good reduction & $78 \%$ & $70.4 \%$ & $90 \%$ \\
\hline 4. & Duration of operation & 80 minutes & 50 minutes & 71 minutes \\
\hline
\end{tabular}

Reduction was considered good if the cortical congruence at the calcar region was restored, and if the displacement between the fragments did not exceed $2 \mathrm{~mm}$ in any projection. The ideal position for the screw in the femoral neck for the PFN was defined as being central on the lateral radiograph and central or inferior on the AP radiograph.

\section{Intra-operative difficulties in each group}

We encountered difficulty in finding entry point if the greater trochanter was broken.

Post operative infection was seen in 2 patients in the PFN group and needed change of antibiotics and dressings. Both were suffering from DM.

Table 10: Radiographic evaluation at final follow-up.

\begin{tabular}{|c|c|c|c|c|}
\hline No & & Our series & J. Pajarinen's series & M. Porecha's Series \\
\hline 1. & Implant failure & $3 \%$ & $4.2 \%$ & $2 \%$ \\
\hline 2. & Neck screw cutout & $0 \%$ & $2.1 \%$ & $0 \%$ \\
\hline 3. & Z effect & $3 \%$ & - & $2 \%$ \\
\hline 4. & Nonunion & $5 \%$ & $4.2 \%$ & $0 \%$ \\
\hline 5. & Peri-implant fracture & $0 \%$ & $0 \%$ & $0 \%$ \\
\hline
\end{tabular}

Complications seen in the PFN group included implant failure (3\%), Z-effect (3\%), and non-union (5\%). The total number of patients with complications were $11 \%$. This can be because of the underlying osteoporosis, improper position of screws (relatively long de-rotation screw), mismatching of implants and variable neck-shaft angle in our series.

\section{Functional analysis at final follow-up}

The weight bearing was started early as per tolerance of the patients if we had achieved good reduction and stable fixation especially in young patients. Due to the lack of upper extremity strength and co-morbidities in the majority of the hip fracture population, the use of an assistive device to fully unload the repaired extremity is limited.

After PFN fixation, by $3^{\text {th }}$ week, partial weight bearing was allowed in $13 \%$ of patients and full weight bearing was allowed to $50 \%$ of patients at the end of 10 week. All the patients had final follow up at 18 months of surgery. (mean11.17 months, maximum-18 months and minimum- 6 months). No notable differences were seen between implants in terms of fracture healing. Based on all the above criteria the functional result according to Harris Hip Score was found to be excellent in $54 \%$, good in $20 \%$, fair in $10 \%$ and poor in $10 \%$ of patients.

\section{Clinical photos}
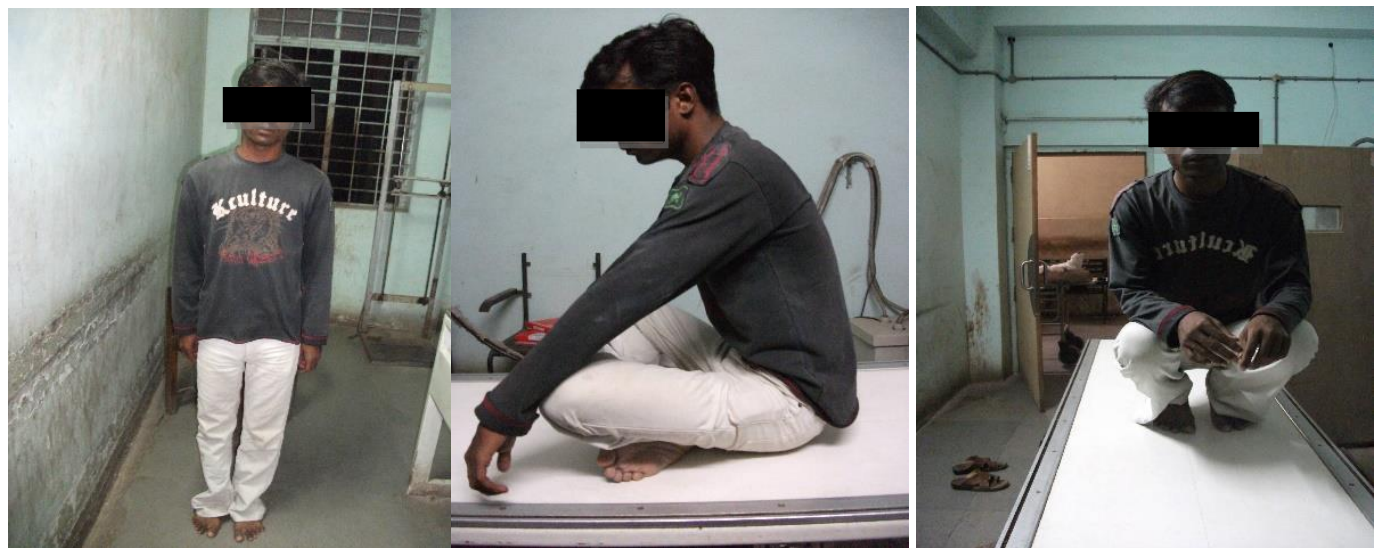


\section{Pre op x-ray}
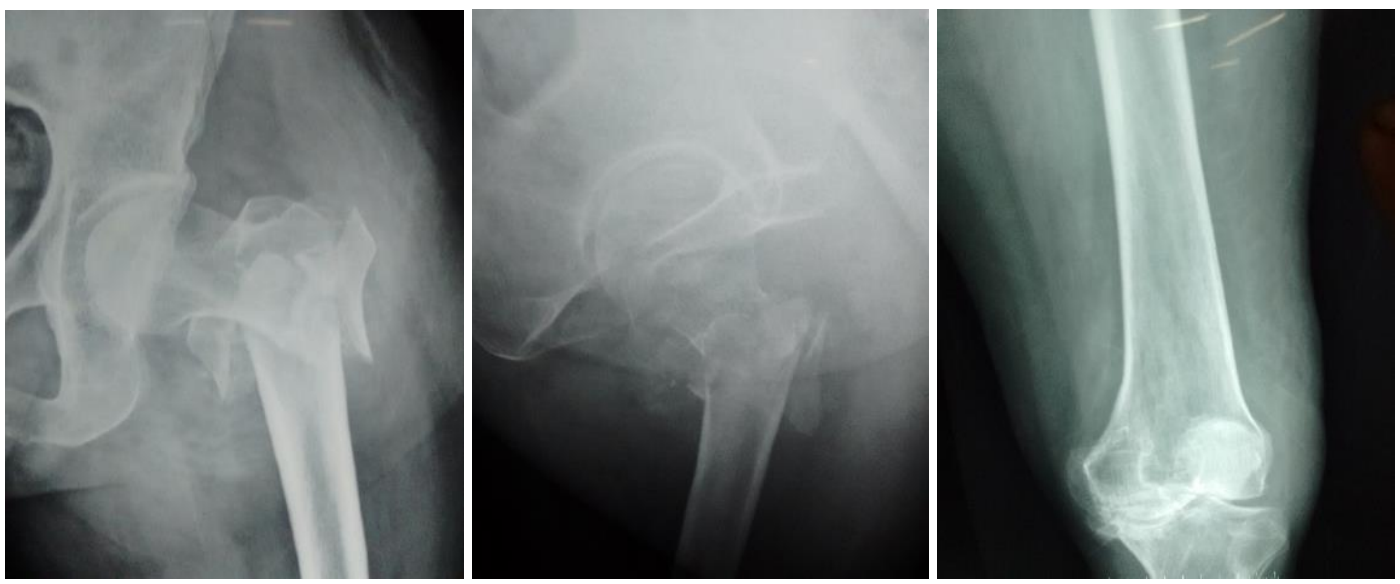

\section{Post Op X-ray}
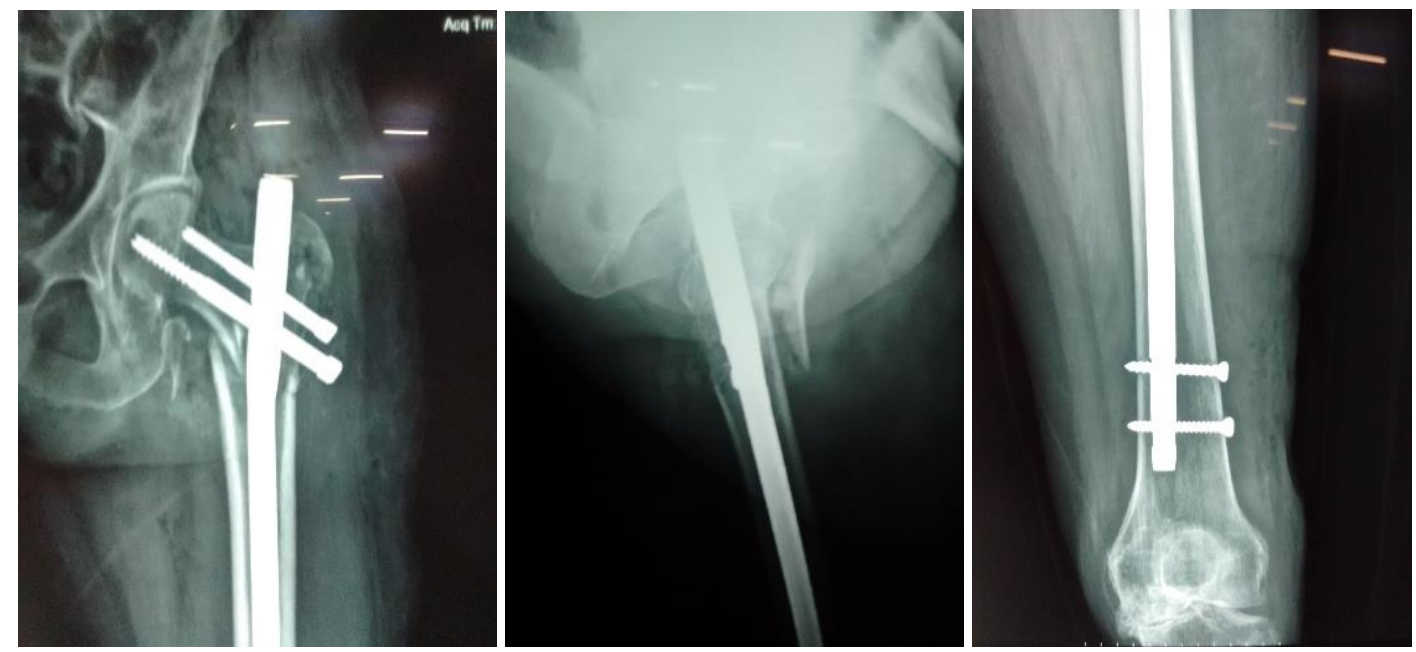

Acta Radiol Scand. 1956; 46:533-546.

\section{References}

1. Murray RC. Trochanteric fractures of femur, JBJS. 1949; 31-B:204.

2. Boyd HB, Griffin LL. Classification and Treatment of Trochanteric Fractures. Arch. Surg. 1949; 58:853:866.

3. Evans EM. Trochanteric Fractures. J Bone Joint Surg., 1951; 33B:192-204.

4. Dimon JH, Hughston JC. Unstable Intertrochanteric Fractures of the Hip. J Bone Joint Surg. 1967; 49A:440450.

5. Ender. Treatment of the intertrochanteric fractures of the hip, JBJS. 1976; 58-A:15.

6. Rao JP, Banzon MT, Weiss AB, Rayhack J. Treatment of Unstable Intertrochanteric Fractures With Anatomic Reduction and proximal femoral nail Fixation. Clin. Orthop. 1983; 175:65.

7. Parker MJ. Valgus reduction of trochanteric fractures Injury. 1993; 24(5):313-6.

8. DeLee JC. Fracture around Hip. In Bucholz RW, Heckman JD, Editors. Rockwood and Green's Fracture in Adults. 5th edition. Philadelphia: Lippincott Williams and Wilkins. 1996; 2:1637-1639.

9. Singh M, Nagrath AR, Maini PS. Changes in Trabecular Pattern of the Upper End of the Femur as an Index of Osteoporosis. J Bone Joint Surg. 1970; 52A:457-467.

10. Trueta. The normal vascular anatomy of the human femoral head during growth. J Bone Joint Surg. 1957; 39(B):358.

11. Mussbichler H. Arterial supply of the head of the femur.
12. Pauwels F. Biomechanics of the Locomotor Apparatus. Springer Verlag, New York, 1980, 1-228.

13. Kenneth Koval J, Robert Cantu V. Chapter 45Intertrochanteric Fractures, Rockwood \& Green's Fractures in Adults, 6th Edition, 1794.

14. Tronzo RG. Special considerations in management. Orthop Clin North Am. 1974; 5:571-583.

15. Cheng CL, Chow SP, Pun WK et al. Long-term results and complications of cement augmentation in the treatment of unstable intertrochanteric fractures, Injury. 1989; 20:134

16. Laros GS. The Role of Osteoporosis in Intertrochanteric Fractures. Orthop. Clin. North Am. 1980; 11:525-537.

17. Kenneth Koval J, Robert Cantu V, Bucholz Robert W, Heckman James D, Court-Brown, Charles M. Rockwood \& Green's Fractures in Adults, 6th Edition, 1804-1808.

18. Al-Yassari G, Langstaff RJ, Jones JWM. The AO/ASIF proximal femoral nail (PFN) for the treatment of unstable trochanteric femoral fracture. Injury. 2002; 33:395-399.

19. Boldin C, Seibert FJ, Fankhauser F et al. The proximal femoral nail (PFN) - a minimal invasive treatment of unstable proximal femoral fractures: a prospective study of 55 patients with a follow-up of 15 months. Acta Orthop Scand. 2003; 74:53-58.

20. Pinder RC, Durnin CW, Cook DA. The Leinbach prosthesis in the treatment of complex intertrochanteric fractures. Paper presented at the annual meeting of the American Academy of Orthopaedic Surgeon, Las vegas, 
1981.

21. Green S, Moore T, Proano F. Bipolar prosthetic replacement for the management of unstable intertrochanteric hip fractures in the elderly, Clin Orthop Relat Res. 1987; 224:169.

22. Mariani EM, Rand JA. Nonunion of intertrochanteric fractures of the femur following open reduction and internal fixation: results of second attempt to gain union, Clin Orthop Relat Res. 1987; 218:81.

23. Taylor GM, Neufeld AJ, Nickel VL. Complications and Failures in the Operative Treatment of Intertrochanteric Fractures of the Femur. J Bone Joint Surg. 1955; 37A:306-316.

24. Mann RJ. Avascular Necrosis of the Femoral Head Following Intertrochanteric Fractures. Clin. Orthop. 1973; 92:108-115.

25. Tronzo RG. Use of an Extramedullary Guide Pin for Fractures of the Upper End of the Femur. Orthop. Clin. North Am. 1974; 55:525-527.

26. Hunter GA. The Results of Operative Treatment of Trochanteric Fractures of the Femur. Injury. 1974-1975; 6:202-205.

27. Kyle RF, Gustilo RB, Premer RF. Analysis of six hundred ans twenty-two intertrochanteric hip fractures. J Bone and Joint Surg. 1979; 61-A:216.

28. Sernbo I, Johnell O. Consequences of a hip fracture: a prospective study over 1 year. Osteoporosis Int. 1993; 3:148-53.

29. de Palma L, Rizzi L, Lorini G, Greco F. Survival after trochanteric fracture: biological factors analyzed in 270 patients. Acta Orthop Scand. 1992; 63:645-7.

30. Barr JS. Diagnosis and Treatment of Infections Following Internal Fixation of Hip Fractures. Orthop. Clin. North Am. 1974; 5:847-864.

31. Versluyjen M. Pressure Sores in Elderly Patients: The Epidemiology Related to Hip Operations. J Bone Joint Surg. 1985; 67B:10-13.

32. Soballe K. Laceration of the superficial femoral artery by an intertrochanteric fracture fragment. J Bone Joint Surg. 1987; 69A:781-783.

33. Minos T, Andreas P. Treatment of extracapsular hip fractures with the proximal femoral nail (PFN): Long term results in 45 patients, Acta Orthop. Belg. 2004; 70:444-454.

34. Pajarinen J, Lindahl J, Michelsson O, Savolainen V, Hirvensalo E. Pertrochanteric femoral fractures treated with a dynamic hip screw or a proximal femoral nail: A randomized study comparing post-operative rehabilitation. J Bone Joint Surg. 2005; 87-B:76-81.

35. Porecha MM, Parmar DS, Chawada HR, Parmar RD. Long proximal femoral nails versus sliding hip screwplate device for the treatment of intertrochanteric hip fractures, A randomized prospective study in 100 elderly patients. The Internet Journal of Orthopedic Surgery. 2009; 12(1):032-035. 